\section{Hospital-based violence intervention: an emerging practice based on public health principles}

\author{
Rochelle A Dicker
}

Violent injury in the USA continues to represent a major public health issue. As reported this year in the American Journal of Medicine, we are 10 times more likely to be killed from violence in the USA than in any other developed country and the rate of gun-related murder is 25 times higher than 22 other high-income countries. According to the CDC, this translated into 492000 potential life years lost, giving credence to the fact that our young people are significantly affected. Minority populations bear the highest risk: homicide is the leading cause of death in African-Americans 15-34 years old and the second leading cause in Hispanics 15-24 years old. For every homicide, at least seven more people are non-fatally injured from violence.

Largely as a result of the horrific surge in mass casualty events, and the notoriety of police-related shootings, violence, particularly gun-related violence, has squarely captured the public's attention, which has in turn galvanised communities, political leaders, special interests and healthcare providers. Our frequent experiences on the job along with powerful statements from many leading medical associations, including the American College of Surgeons and the American Association for the Surgery of Trauma, have in turn precipitated dialog and action among the membership. Dr Deborah Kuhls recently presented a survey of the members of the Committee on Trauma regarding firearm injury. The vast majority of the membership felt that firearm injury prevention should be a priority. The questions remain: (1) how do we stop the cycle of violence through prevention and address this public health issue and (2) how do we measure effectiveness.

As with other public health issues, violent injury has recognizable risk factors and protective factors. The literature

San Francisco General Department of Surgery, University of California, San Francisco, San Francisco, California, USA

Correspondence to Dr Rochelle A Dicker, MD, Rochelle.Dicker@ucsf.edu about these factors and their application to violence prevention can be found back in the 1990s with publications such as Health and Human Services, Youth Violence: A Report of the Surgeon General, and groundbreaking contributions by Dr Deborah Prothrow-Stith. Risk factors are largely based on the social determinants of health, such as socioeconomics, education, and environment. Addressing these factors could lead to a reduction in future risk of injury or injury recidivism. In a related manner, protective factors such as strong mentorship and the development of life skills could play a significant role in empowerment and the development of social capital. The 'trauma-informed approach', highlighted by such groups as Substance Abuse and Mental Health Services Administration (SAMHSA), the most dominant emerging approach in the field of violence intervention, not only looks to reduce contributory risk factors but also acknowledges the importance of mental healthcare and the avoidance of re-traumatization. The CDC has highlighted this type of approach as a solid example of addressing the social determinants of health to solve a public health problem and distributes it as a primer ('Health and Well-being for All: Meeting in a Box').

Over the past 10 years, several hospitalbased violence intervention programs have emerged. Six charter programs, championed by trauma surgeons, emergency medicine physicians and public health professionals, created the National Network of Hospital-Based Violence Intervention Programs (NNHVIP). The fidelity in the practice is based on (1) violent injury serving as a teachable moment, (2) culturally competent case management and (3) addressing risks associated with violent injury. The group is dedicated to assisting fledgling programs, and it strives to be rigorously evaluating program effectiveness along the spectrum of public health evaluation principles from feasibility to long-term outcomes. Although there are over 35 programs nationwide that are part of NNHVIP, the field remains new and there is much to be learnt through safe practices and refinements based on lessons learnt. Few randomized controlled trials have been undertaken, largely because both the communities most affected by violence, and some Institutional Review Boards do not have the equipoise necessary to approve of this type of study. There have been successes in reduction of recidivism, and there are data supporting the costeffectiveness of these programs, but there are also pitfalls. As an example, one program just completed a 10 -year retrospective evaluation: 'A decade of hospitalbased violence intervention: benefits and shortcomings' soon to be published in the Journal of Trauma and Acute Care Surgery. The authors found that finding 'stable housing' may actually represent a risk factor for reinjury. One participant was coming home from an arborist job, developed by his violence intervention program and was shot as he was entering his own home. Community factors, not just individual factors, play a strong role in this difficult issue.

The authors of 'Hospital-based violence intervention programs targeting adults: an eastern association for the surgery of trauma evidence based review' evaluated existing literature for effectiveness of hospital-based programs and found that based on their review, they could not make recommendations regarding these programs. The work is an important call for more data and hopefully will serve as a strong advocacy piece for more funding to support these types of programs and programmatic evaluation. As we move forward with the validated principles of the public health model in our approach to our vulnerable populations, we also need to take into consideration the importance of qualitative measures in assigning 'value' to these programs. To use the above example, the individual in the arborist program indeed was reinjured, but his life trajectory has changed nonetheless as he is at work in a solid job that is of interest to him. Additionally, he is volunteering in counseling youth who are at risk for violence.

Perhaps the most promising aspect of violence intervention is that it has garnered the attention commensurate with the burden, and there is a critical mass of people caring for the injured who are actively seeking to be part of addressing the underpinnings of violence. The review article represents the drive to find viable solutions. Today, we have a safe, feasible 
model that is being disseminated and needs more rigorous investigation. We need time and a mixed methods approach to demonstrate value and outcomes in hospital-based violence intervention. It is critical that we articulate in our manuscripts the importance of further research so that the funding streams follow the drive in this fairly new field. The California Wellness Foundation is currently funding a multi-institutional database that will certainly shed some light on these programs. It already has over 6000 participants in it. Ultimately, it is studies like this and many qualitative and quantitative evaluations currently underway in programs within the NNHVIP that we hope will provide the data necessary to advocate for a trauma-informed approach to be part of the fabric of trauma centers that experience a high burden of violent injury. We can move the needle on this public health issue with persistence, science, humility, continued engagement and focus on our communities at risk.

Competing interests None declared.

Provenance and peer review Commissioned; internally peer reviewed.

Open Access This is an Open Access article distributed in accordance with the Creative Commons Attribution Non Commercial (CC BY-NC 4.0) license, which permits others to distribute, remix, adapt, build upon this work non-commercially, and license their derivative works on different terms, provided the original work is properly cited and the use is noncommercial. See: http://creativecommons.org/licenses/ by-nc/4.0/

To cite Dicker RA. Trauma Surg Acute Care Open Published Online First: [please include Day Month Year] doi:10.1136/tsaco-2016-000050

Received 4 October 2016

Accepted 13 October 2016

\section{SLinked}

http://dx.doi.org/10.1136/tsaco-2016-000024

Trauma Surg Acute Care Open 2016;1:1-2. doi:10.1136/tsaco-2016-000050 